\title{
Prevalence of soil-transmitted helminth infection among children under 2 years from urban and rural settings in Ogun state, Nigeria: implication for control strategy
}

\author{
Olufunmilayo A. Idowu, Ayodele S. Babalola* (1) and T. Olapegba
}

\begin{abstract}
Background: Pre-school-aged children are always excluded in mass intervention policies for control of soil-transmitted helminths in Nigera. The need for evidence on infectivity of children in this age group cannot be overemphasized. This study seeks to determine the prevalence of STH among 103 children who are less than 2 years of age in an urban and rural area of Ogun State, Nigeria. This study through questionnaire administration also obtained relevant demographic information and hygiene behavior from parents of children recruited to this study.

Results: The overall prevalence of $69.9 \%$ was recorded, with Ascaris lumbricoides occurring as the most prevalent helminth (68.0\%). This was followed by Hook worm (49.5\%) and Trichris trichuria (18.5\%). A significant increase in prevalence of hookworm was observed with increase in age $(p<0.05)$. Generally, A. Lumbricoides was found to be more prevalent as a single infection in the study population. Most of the T. Trichuria and hookworm infections were either in co-infections infections with A. Lumbricoides. The prevalence of A. Lumbricoides and Hookworm were significantly high in rural community when compared with urban $(p<0.05)$. Poor hygiene practices were common among the study participants.

Conclusions: The prevalence of STH infection is incredibly high in this age group that was for a long time considered as less important when it comes to burden due to STH. Therefore, there is a need to include them into future plans for control interventions.
\end{abstract}

Keywords: Children, Hygiene, Nigeria, Prevalence, Soil-transmitted helminths

\section{Background}

Soil transmitted helminth (STH) infections is tagged as one of the most common and neglected infections at worldwide [1]. This disease is very rampant with humans living in areas of poverty in the developing world. About one billion individuals were reported to carry helminthic worms, in which most of them are living in low socioeconomic settings, in sub-Saharan Africa [2, 3]. Studies

*Correspondence: ayodelebabalola2011@gmail.com Present Address: Department of Pure and Applied Zoology, Federal University of Agriculture, Abeokuta, Nigeria have shown that children are the most vulnerable groups affected by helminths [4-6]. Epidemiological surveys have demonstrated that poor sanitary conditions such as defecation and fecal contamination of water bodies are the most important factors leading to intestinal worm infestation [7] while the spread is due to personal hygiene [8]. Nigeria, is endemic for helminth infections, in which ascariasis, trichuriasis, and hookworm were incriminated as the major cause, with estimated cases of 55 million, 34 million, and 38 million, respectively $[9,10]$.

Both pre-school and school age children (0-15 years) are the groups at risk of getting infected [4-6]. The 
effects of helminthic infection in children are very detrimental. Furthermore, chronic infection is highly associated with malabsorption, inflammation, reduced immunity etc., leading to long-term morbidity such as growth retardation [11], impaired cognition/school performance, [12] etc. This vicious cycle is most detrimental in early childhood when the child is most dependent on nutritional resources for its physical and mental development.

Major interventions (in terms of treatment and/or preventive chemotherapy) that were put in place to curb the menace of helminth infections in Nigeria had basically catered for school aged children [13] and sometimes adults. This implies that pre-school aged (0-4years) children were left out leaving them at the mercies of their parents who may not be able to afford proper health care for affected child especially in the rural communities.

In view of the general neglect of this age group in helminth control strategies, it is important to provide evidences to justify more integrative control approaches. However, most studies focused more on school aged children with few reports on pre-school-aged children [4, 14-16]. With this background, this study therefore seeks to determine the prevalence of STH among children less than 2 years in an urban and rural area of Ogun State.

\section{Methods}

\section{Study area}

This study was carried out in a purposively selected rural and urban communities "Olugbo and Obantoko, respectively" located Odeda Local Government Area of Ogun state, Nigeria. The inhabitants of the urban areas primarily depend on boreholes for water resource and dug wells as supplement, with good toilet facilities. On the other hand, the inhabitants of the rural communities primarily depend on streams for water resource, poor toilet facility. Hygiene and sanitation practices and waste disposal facilities are inappropriate in the rural area.

\section{Study participants}

Community members of the selected area were sensitized about the research through the assistance of Primary Health Care (PHC) center staffs and the Community Development Association (CDA) leaders. A total sampling of households within the community was done and consenting parents with children belonging to age category $0-2$ years were recruited into the study. Parents of children who could provide adequate stool specimen at the point of visit were asked to converge at the PHC center where samples were collected and questionnaires were administered.

\section{Questionnaire administration}

Parents/caregivers whose children could provide adequate stool specimen were interviewed using a structured questionnaire at the PHC centre. Age and sex of each child, household sanitary, and personal hygiene conditions were documented using the questionnaire.

\section{Laboratory procedure}

One gram of the stool sample collected from each preschooler was prepared using sodium-acetate-acetic acid-formalin (SAF) ether concentration technique to increase the sensitivity of STH ova detection [17]. Samples were emulsified in $10 \mathrm{~mL}$ of SAF solution and transported in ice packs to the parasitology laboratory, for analysis within $2 \mathrm{~h}$ of collection. In the laboratory, sample bottles were vigorously agitated to efficiently suspend the stool in the solution. Stool suspension was further strained through a $13-\mathrm{mm}$ sieve into a centrifuge tube, and the filtrate was centrifuged at $2000 \mathrm{rpm}$ for $5 \mathrm{~min}$. The resulting supernatant was discarded; then $7 \mathrm{~mL}$ of normal saline and $3 \mathrm{~mL}$ of petroleum ether were added to the sediment. The resulting mixture was shaken vigorously and centrifuged for $5 \mathrm{~min}$ at $2000 \mathrm{rpm}$. The first three layers of the suspension observed after centrifuging were discarded leaving the last layer of sediment. Sediment was pipette onto clean, oil-free glass slide and examined for the ova of gastrointestinal helminths under $\times 10$ objective lens [17].

\section{Statistical data analysis}

All statistical analyses were performed using IBM SPSS 20.0 version, Armonk, NY, IBM Corp. Data obtained were first subjected to descriptive statistics including frequencies and cross-tabulations, followed by Pearson chi-square analysis to test for variables that were significantly associated with infection among the surveyed population. Probability values less than 0.05 were considered significant. Parasite species combinations and specific co-infection prevalence were illustrated using Venn diagrams.

\section{Results \\ Demographic characteristics of the respondents}

Only 103 children (50 urban, 53 rural) were able to provide amount of stool samples $(1 \mathrm{~g})$. Majority of the study participants $40(38.8 \%)$ were within the age range of 0-6 months, which was followed by infants within the age range 19-24months 25 (24.3\%). The least proportion of the children $14(13.6 \%)$ fell within the age range $13-18$ months. Furthermore, slightly more 
Table 1 Demographic characteristics of the pre-school aged children

\begin{tabular}{lll}
\hline Variables & $\begin{array}{l}\text { Frequency } \\
\mathbf{N = 1 0 3}\end{array}$ & $\begin{array}{l}\text { Percentage } \\
\text { (\%) }\end{array}$ \\
\hline $\begin{array}{lll}\text { Age (months) } \\
0-6\end{array}$ & 40 & 38.8 \\
$7-12$ & 24 & 23.3 \\
$13-18$ & 14 & 13.6 \\
$\quad$ 19-24 & 25 & 24.3 \\
Sex & & \\
$\quad$ Male & 49 & 47.6 \\
$\quad$ Female & 54 & 52.4 \\
No. of children $0-2$ years & & \\
$\quad$ Urban & 50 & 48.5 \\
Rural & 53 & 51.5 \\
\hline
\end{tabular}

Table 2 Prevalence of individual STHs among children aged 0-2years from selected rural and urban communities

\begin{tabular}{lllll}
\hline Community & $\begin{array}{l}\text { No. } \\
\text { examined }\end{array}$ & $\begin{array}{l}\text { Parasites } \\
\boldsymbol{N}(\%)\end{array}$ & & \\
\cline { 3 - 5 } & & $\begin{array}{l}\text { A. } \\
\text { Lumbricoides }\end{array}$ & T. trichuria & Hook worm \\
\hline Urban & $50(48.5)$ & $28(56.0)^{*}$ & $8(16.0)$ & $19(38.0)^{*}$ \\
Rural & $53(51.5)$ & $42(79.2)$ & $11(20.8)$ & $32(60.4)$ \\
Total & $103(100.0)$ & $70(68.0 \%)$ & $19(18.5)$ & $51(49.5)$ \\
\hline
\end{tabular}

Values asterisk $\left(^{*}\right)$ connotes significant difference in a column females participated in the study compared to males (Table 1).

\section{Prevalence of individual STHs among children aged 0-2 years from selected rural and urban communities}

The overall prevalence of STH in this study was $69.9 \%$. Three soi-transmitted helminths; Ascaris lumbricoides, Trichuris trichuria, and Hookworms were prevalent among the study population, with A. Lumbricoides recording the highest prevalence (68.0\%). This was followed by hookworm (49.5\%) and T. Trichuria (18.5\%) (Table 2). Furthermore, these infections were significantly more prevalent in the rural community compared to the urban community (Table 2).

\section{Prevalence of STHs by age and sex among children} 0-2 years from selected rural and urban communities Generally, there was a significant difference in prevalence of STH from the two communities $(p<0.05)$, with $79.2 \%$ and $60.0 \%$ of the children from rural and urban community being positive for at least one of the three STHs, respectively (Table 3). However, the highest prevalence was observed to occur among children that fell between 19 and 24 months in both communities, while the least prevalence was found among children within the age range $0-6$ months (Table 3). Furthermore, infection with A. lumbricoides and Hookworm was significantly higher among children aged 19-24months while the least prevalence were recorded among children aged 0-6months (Table 4).

More males were infected from both communities; however, this does not reach a statistically significant level $[p>0.05]$ (Table 3). Similarly, no significant parasite

Table 3 Prevalence of STHs by age and sex among children aged 0-2years from selected rural and urban communities

\begin{tabular}{|c|c|c|c|c|c|c|}
\hline \multirow{2}{*}{$\begin{array}{l}\text { Variables } \\
\text { Age (months) }\end{array}$} & \multicolumn{2}{|l|}{$\begin{array}{l}\text { Rural } \\
N(\%)\end{array}$} & \multicolumn{2}{|l|}{$\begin{array}{l}\text { Urban } \\
N(\%)\end{array}$} & \multicolumn{2}{|l|}{$\begin{array}{l}\text { Grand total } \\
N(\%)\end{array}$} \\
\hline & Number examined & Number + ve & Number examined & Number + ve & Number examined & Number + ve \\
\hline $0-6$ & $13(24.5)$ & $3(23.1)$ & $27(54.0)$ & $12(44.4 \%)$ & $40(38.8)$ & $15(37.5)$ \\
\hline $7-12$ & $16(30.2)$ & $15(93.8)$ & $8(16.0)$ & $7(87.5)$ & $24(23.3)$ & $22(91.7)$ \\
\hline $13-18$ & $9(17.0)$ & $9(100.0)$ & $5(10.0)$ & $2(40.0)$ & $14(13.6)$ & $11(78.6)$ \\
\hline $19-24$ & $15(28.3)$ & $15(100.0)$ & $10(20.0)$ & $9(90.0)$ & $25(24.3)$ & $24(96.0)$ \\
\hline Total & $53(100.0)$ & $42(79.2)$ & $50(100.0)$ & $30(60.0)$ & $103(100.0)$ & 72 (69.9) \\
\hline$P$ values & & $0.012^{*}$ & & $0.042^{*}$ & & $0.035^{*}$ \\
\hline \multicolumn{7}{|l|}{ Sex } \\
\hline Male & $27(50.9)$ & $22(81.5)$ & $22(44.0)$ & 14 (63.6) & $49(47.6)$ & $36(73.5)$ \\
\hline Female & $26(49.1)$ & $20(76.9)$ & $28(56.0)$ & $16(57.1)$ & $54(52.4)$ & $36(66.7)$ \\
\hline Total & $53(100.0)$ & $42(79.2)$ & $50(100.0)$ & $30(60.0)$ & $103(100.0)$ & $72(69.9)$ \\
\hline$P$-values & & 0.126 & & 0.112 & & 0.132 \\
\hline
\end{tabular}

Values asterisk $(*)$ connotes significant difference in a column 
Table 4 Prevalence of STHs by age and gender across different parasite types

\begin{tabular}{|c|c|c|c|c|c|}
\hline \multirow[t]{2}{*}{ Variables } & \multirow[t]{2}{*}{ Number examined } & \multirow[t]{2}{*}{ Number + ve } & \multicolumn{3}{|l|}{ Parasite type } \\
\hline & & & A. lumbricoides & T. trichuria & Hookworm \\
\hline \multicolumn{6}{|c|}{ Age (months) } \\
\hline $0-6$ & $40(38.8)$ & $15(37.5)$ & $14(35.0)$ & $0(0.0)$ & $8(20.0)$ \\
\hline $7-12$ & $24(23.3)$ & $22(91.7)$ & $21(87.5)$ & $1(4.2)$ & $19(79.2)$ \\
\hline $13-18$ & $14(13.6)$ & $11(78.6)$ & $11(78.6)$ & $7(50.0)$ & $10(71.4)$ \\
\hline 19-24 & $25(24.3)$ & $24(96.0)$ & $24(96.0)$ & $11(44.0)$ & $23(92.0)$ \\
\hline Total & $103(100.0)$ & $72(69.9)$ & $70(68.0)$ & $19(18.4)$ & $60(58.3)$ \\
\hline$P$ values & & $0.035^{*}$ & $0.012^{*}$ & $0.037^{*}$ & $0.041^{*}$ \\
\hline \multicolumn{6}{|l|}{ Sex } \\
\hline Male & 49 (47.6) & $36(73.5)$ & $34(69.4)$ & $8(16.3)$ & $31(63.3)$ \\
\hline Female & $54(52.4)$ & $36(66.7)$ & $36(66.7)$ & $11(20.4)$ & $28(51.9)$ \\
\hline Total & $103(100.0)$ & $72(69.9)$ & $70(68.0)$ & $19(18.4)$ & $60(58.3)$ \\
\hline$P$ values & & 0.132 & 0.672 & 0.215 & 0.087 \\
\hline
\end{tabular}

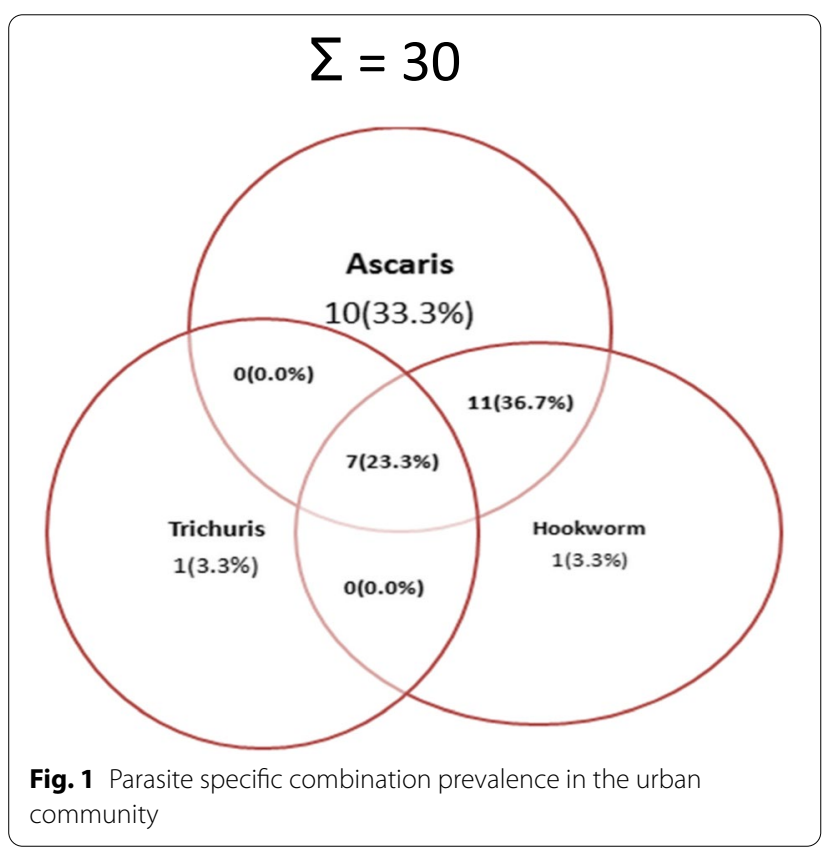

specific prevalence was recorded with respect to gender in the study population (Table 4).

\section{Helminth parasite-specific combination prevalence in the study population}

Generally, A. Lumbricoides was found to be more prevalent as a single infection from both communities with the highest occurrence from the urban community (Figs. 1 and 2). Most of the T. Trichuria and hookworm infections were either in co-infections or multiple infections as revealed in the venn diagram (Figs. 1 and 2). More so, only 1 case each

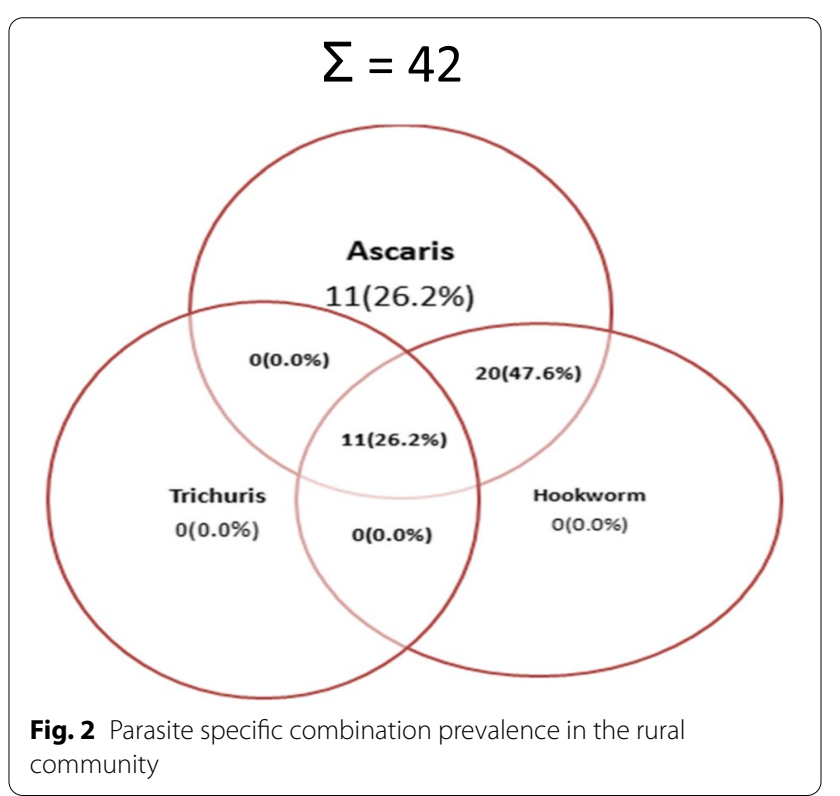

of T. Trichuria and hookworm occurred as a single infection and was found in the urban community.

We observed that co-infection of A. Lumbricoides and Hookworm were more prevalent among the children from both communities. This was followed by multiple infections of the three helminths (Figs. 1 and 2). Futhermore, no co-infection existed between [A. lumbrociodes and T. trichuria] as well as [T. trichuria and hookworm] in this study (Figs. 1 and 2). 
Table 5 Hygiene attitudes and practices of the surveyed preschool aged children ( $<2$ years)

\begin{tabular}{|c|c|c|c|}
\hline Practices & $\begin{array}{l}\text { Urban } \\
N(\%)\end{array}$ & $\begin{array}{l}\text { Rural } \\
N(\%)\end{array}$ & $\begin{array}{l}\text { Total } \\
N(\%)\end{array}$ \\
\hline Toilet in use & $N=53$ & $N=50$ & $103(100)$ \\
\hline Open pit & $18(33.9)$ & $27(54.0)$ & $45(43.7)$ \\
\hline Water closet & $26(49.1)$ & $0(0.0)$ & $26(25.2)$ \\
\hline Bush & $09(17.0)$ & $23(46.0)$ & $32(31.1)$ \\
\hline Washing of hands after playing & $N=53$ & $N=50$ & $103(100)$ \\
\hline Yes & $14(26.4)$ & $07(14.0)$ & $21(20.4)$ \\
\hline No & $39(73.6)$ & $43(86.0)$ & $82(79.6)$ \\
\hline Washing of hands before feeding & $N=53$ & $N=50$ & $103(100)$ \\
\hline Yes & $19(35.8)$ & $18(36.0)$ & $37(35.9)$ \\
\hline No & $34(64.2)$ & $32(64.0)$ & $66(64.1)$ \\
\hline Wearing of sandals when playing & $N=53$ & $N=50$ & $103(100)$ \\
\hline Yes & $10(18.9)$ & $4(8.0)$ & $14(13.6)$ \\
\hline No & $43(81.1)$ & $46(92.0)$ & $89(86.4)$ \\
\hline
\end{tabular}

Hygiene, attitude, and practice of pre-schoolers from selected urban and rural communities

More of the respondents (parents) from rural community (54\% compared with $33.9 \%$ from urban) use open pit. This is followed by 23(46.7\%) that uses open defecation. However, majority of the parents/care givers from urban (49.1\%) reported that they throw their children feces into water closet after using the potty, while about $17 \%$ uses open defecation (Table 5).

Furthermore, majority of the parents/caregivers from both urban and rural communities claimed they do not wash their children hands after defecation. In the same vein, about $64 \%$ of the mothers from urban and rural communities respectively do not wash their hands before feeding their children (Table 5).

A high proportion (81.1\%) of the children from urban community does not wear sandals while playing, while only $8 \%$ of the children from rural communities wear sandal while playing (Table 5).

\section{Discussion}

It is imperative to constantly evaluate the prevalence of intestinal helminths among children owing to the illeffects posed by these parasites among the vulnerable groups.

This study revealed a very high infection levels already in this age group and a clear exposure time relationship with more infections in older ages. A rural-urban difference occurred in terms of prevalence, with similar prevalence by sex.

The high prevalence recorded for A. lumbricoides (69.9\%) and hookworm (49.5\%) is a pointer to showcase the vulnerability of the children less than 2 years to intestinal helminths, and this justifies the need to include them in deworming programs.

Just as it occurs in several studies from Nigeria [1820], A. lumbricoides was found to be more prevalent, followed by Hookworm and T. trichuria, respectively. However, some studies reported higher prevalence of hookworm [15, 21]. The difference observed could be attributed to low socio-economic status especially among the rural communities. Studies have demonstrated an inverse relationship between socio-economic status and prevalence of $A$. lumbricoides [16]. The low socio-economic status (e.g., lack of toilet facilities and being unable to afford sandal for their children) as well as poor hygiene practices demonstrated by the rural participants from the rural community used in this study could explain why significantly high proportion of the respondents were infected with $A$. lumbricodes and Hookworm compared with their urban counterparts.

The fact that there was no significant difference in STH prevalence between girls and boys is likely to be related with the age group. In this age group, the children do not yet show major differences in activities they seek by own motivation and that exposes them [22]. They still largely depend on caretakers who provide them food and water and clean them. This picture changes when it comes to school-aged children, where boys mostly show higher infection levels than girls owing to more risky outdoor and hygiene behavior.

Nevertheless, a high proportion of the children between ages 19 and 24 months were positive to helminth infection compared with other age brackets. It is important to note that at that age, most children would have been walking actively, and studies have shown that children are more likely to walk barefooted [23], hereby exposing them to hook worm infections. Apart from this, studies have showed that in developing countries, young children crawl and play in areas where they may come into contact with soil that is contaminated with human and animal feces [24]. All this factors linked with the poor standard of living and a hygiene practice predisposes these young children to STHs and this poses a serious threat on their growth and development.

On the other hand the primary food and fluid for children $\leq 1$ year is breast milk and are not able to crawl to areas where they could come in contact with parasites. This explains the low prevalence observed among the younger babies.

Poly-parasitism or multiple infections were high for "Ascaris + Hookworm" from both communities (being more prevalent in rural community) and followed by the combination of the three STHs. Common 
predisposing factors that could link all of them together is low standard of living and poor hygiene practices [16].

To reduce or stop the transmission of STHs, there is need to break the transmission cycle; however, this study showed that the current living standard coupled with poor hygiene practices among the study population is rather strengthening the cycle instead of breaking it.

\section{Conclusion}

STHs are prevalent among the study population, hence some considerations should be given to children under two with respect to deworming programs. This can be through production of less stronger drugs than can be administered to them during mass deworming programmes.

\author{
Abbreviations \\ STH: Soil-transmitted helmiths; PHC: Primary health care; CDA: Community \\ Development Association; A. Lumbricoides: Ascaris Lumbricoides; T. trichuria: \\ Trichuris trichuria; SAF: Sodium-acetate-acetic acid-formalin.
}

\section{Acknowledgements}

We acknowledge the community heads of the two communities used in this study. We are also grateful for the willingness of the parents to allow their children participate in this study.

\section{Authors' contributions \\ Author IOA conceptualized this research. BAS and IOA designed the research protocol and methodology. BAS, IOA, and OT carried out the field work. BAS and OT provided literatures and other technical inputs. BSA did the statistical analysis and developed the manuscript. The authors read, corrected, and approved the final manuscript.}

\section{Funding}

This research did not receive any specific grant from funding agencies in the public, commercial, or not-for-profit sectors.

\section{Availability of data and materials}

The datasets generated during and/or analyzed during the current study are not publicly available due [General agreement among the authors] but are available from the corresponding author on reasonable request.

\section{Declarations}

\section{Ethics approval and consent to participate}

The ethical committee of the Ministry of Health, Oke-Mosan, Abeokuta Ogun State, provided the ethical approval to conduct this study with reference number PHC/173/10. The research protocol was introduced to the community leader through the already consented primary health care (PHC) coordinator. The research idea was then later translated to the community members (parents and caregivers) through the community development association (CDA). Informed consent forms were verbally translated to the parents and caregiver in their local language; only children of parents/care givers who consented by signing the consent form were recruited into the study.

\section{Consent for publication}

Not applicable.

\section{Competing interests}

The authors declare that they have no competing interests.
Received: 28 July 2020 Accepted: 17 December 2021

Published online: 14 February 2022

\section{References}

1. Sumo L, Otiobo-Atibita EN, Mache E, Gangue T, Nana-Djeunga HC (2021) Transmission of soil transmitted helminthiasis in the Mifi Health District (west region, Cameroon): low endemicity but still prevailing risk. Parasitologia 21(1):95-104. https://doi.org/10.3390/parasitologia1030011

2. World Health Organization (2020) Soil-transmitted helminth infections: key facts; updated 2 march 2020. Available online: https://www.who. int/news-room/fact-sheets/detail/soil-transmitted-helminth-infections (accessed on 29 Nov 2021)

3. World Health Organization (WHO, 2014) Eliminating soil-transmitted helminthiasis as a public health problem in children: progress report 2001-2010 and strategic plan 2011-2020. WHO press, World Health Organization, Geneva, Switzerland Pp1-78

4. Obeta MU, Ejinaka OR, Jwanse RI, Lote-Nwaru IE, Ibrahim AS (2019) Prevalence and distribution of soil-transmitted helminths among children attending township primary school, Jos, plateau state, Nigeria. London J Med Health Res 19(1):55-62

5. Fentiman A, Hall A, Bundy D (2001) Health and cultural factors associated with enrollment in basic education: a study in rural Ghana. Soc Sci Med 52:429-439

6. Albonico M, Ramsan M, Wright V, Jape K, Haji HJ, Taylor M, Savioli L, Bickle Q (2002) Soil-transmitted nematode infections and mebendazole treatment in Mafia Island school children. Ann of Trop Med Parasitol 96:717-726

7. Brooker S, Hotez PJ, Bundy DA (2008) Hookworm-related anaemia. Among pregnant women: a systematic review. PLoS. Negl. Trop. Dis 2:e291

8. Van Eijk AM, Lindblade KA, Odhiambo F (2009) Geohelminth infections among pregnant women in rural Western Kenya; a cross-sectional study. PLoS Negl Trop Dis 3:e370

9. Hotez PJ, Kamath A (2009) Neglected tropical diseases in sub-Saharan Africa: review of their prevalence, distribution, and disease burden. PLoS Negl. Trop. Dis 3(8):e412

10. Hotez PJ, Asojo AO, Adesina AM (2012) Nigeria:'ground zero' for the high prevalence neglected tropical diseases. PLoS Negl. Trop. Dis. 6(7): e1600

11. Rai SK, Hirai K, Abe A, Ohno Y (2002) Infectious diseases and malnutrition status in Nepal: an overview. Malaysian J Nutr 8(2):191-200

12. Lwanga F, Kirunda BE, Orach CG (2012) Intestinal helminth infections and nutritional status of children attending primary schools in Wakiso district, Central Uganda. International J Env Res \& Pub Health 9(8):2910-2921

13. Kirwan P, Asaolu SO, Molloy SF, Abiona TC, Jackson AL, Holland CV (2009) Patterns of soil-transmitted helminths infection and impact of fourmonthly albendazole treatments in preschool children from semi-urban communities in Nigeria: a double-blind placebo-controlled randomised trial. BMC Infect Dis 9:20. https://doi.org/10.1186/1471-2334-9-20

14. Ogunkanbi AE, Sowemimo OA (2014) Factors associated with Ascariasis among pre-school aged children in lle-ife, Osun state, Nigeria. J Par \& Vec Biol 6(8):117-123

15. Taiwo OT, Sam-Wobo SO, Idowu OA, Talabi AO, Taiwo M (2017) Comparative assessment of intestinal helminths prevalence in water, sanitation and hygiene (WASH) intervention and non-intervention communities in Abeokuta, Nigeria. Asian Pac J Trop Biomed 7(6):524-532

16. Ojurongbe O, Oyesiji KF, Ojo JA, Odewale G, Adefioye OA, Olowe AO (2014) Soil transmitted helminth infections among primary school children in Ile-lfe southwest, Nigeria: a cross-sectional study. Int Res J Med Med Sci 2(1):6-10

17. Glinz D, Silu'e KD, Knopp S (2010) Comparing diagnostic accuracy of KatoKatz, Koga Agar Plate, Ether-Concentration, and FLOTAC for Schistosoma mansoni and soil-transmitted helminths. PLoS Negl. Trop. Dis 4(7):e754

18. Omitola OO, Mogaji HO, Oluwole AS, Adeniran AA, Alabi OM, Ekpo UF (2016) Geohelminth infections and nutritional status of preschool aged children in a periurban settlement of Ogun state. Scientifica.:1-9

19. Nmorsi OPG, Isaac C, Aashikpelokhai IS, Ukwandu NCD (2009) Geohelminthiasis among Nigerian preschool age children. Intl J Med \& Med Sci 1(10):407-411 
20. Mordi RM, Ngwodo POA (2007) A study of blood and gastro-intestinal parasites in Edo state. Afr J Biotechnol 6(19):2201-2207

21. Kamalu NA, Uwakwe FE, Opara JA (2013) Prevalence of intestinal parasite among high school students in Nigeria. Acad J Interdiscip Stud 2(7):9-16

22. Parajulia RP, Fujiwarab T, Umezakia KS, Takanea EM, Tachibanae K, Jiangf HW, Paharig K, Watanabea C (2014) Prevalence and risk factors of soiltransmitted helminth infection in Nepal. Trans R Soc Trop Med Hyg 114:1-9

23. Abraar K, Gretchen BC, Alison G (2012) The influence of poverty and culture on the transmission of parasitic infections in rural Nicaraguan villages. J Parasitol Res 2012:1-12

24. Francis MN, Jean H, Humphrey MN, Mbuya N (2013) Formative research on hygiene behaviors and geophagy among infants and young children and implications of exposure to fecal bacteria. Am J Trop Med Hyg 89(4):709-716. https://doi.org/10.4269/ajtmh.12-0568

\section{Publisher's Note}

Springer Nature remains neutral with regard to jurisdictional claims in published maps and institutional affiliations.

\section{Submit your manuscript to a SpringerOpen ${ }^{\circ}$ journal and benefit from:}

- Convenient online submission

- Rigorous peer review

- Open access: articles freely available online

- High visibility within the field

- Retaining the copyright to your article

Submit your next manuscript at $\boldsymbol{\nabla}$ springeropen.com 